\title{
Association Between Age and Sleep Quality: Findings From a Community Health Survey
}

\author{
Minjung Kim, MD, Yoo-Hyun Um, MD, PhD, Tae-Won Kim, MD, PhD, Sung-Min Kim, MD, \\ Ho-Jun Seo, MD, PhD, Jong-Hyun Jeong, MD, PhD, Jihyung Lee, MD, Suhyung Kim, MD, \\ In Hee Cho, MD, Suk-Young Kim, MD, Seung-Chul Hong, MD, PhD \\ Department of Psychiatry, College of Medicine, The Catholic University of Korea, Seoul, Korea
}

\author{
Received: November 30, 2021 \\ Revised: December 3, 2021 \\ Accepted: December 24, 2021 \\ Correspondence \\ Seung-Chul Hong, MD, PhD \\ Department of Psychiatry, \\ St. Vincent's Hospital, \\ College of Medicine, \\ The Catholic University of Korea, \\ 93 Jungbu-daero, Paldal-gu, \\ Suwon 16247, Korea \\ Tel +82-31-249-7114 \\ Fax +82-31-249-6758 \\ E-mail hscjohn@hotmail.com
}

ORCID

Minjung Kim

https://orcid.org/0000-0003-3274-6993

Yoo-Hyun Um

https://orcid.org/0000-0002-3403-4140

Tae-Won Kim

https://orcid.org/0000-0003-2689-202X

Sung-Min Kim

https://orcid.org/0000-0002-3082-4014

Ho-Jun Seo

https://orcid.org/0000-0003-1661-1394

Jong-Hyun Jeong

https://orcid.org/0000-0003-3570-7607

Jihyung Lee

https://orcid.org/0000-0001-6780-1388

Suhyung Kim

https://orcid.org/0000-0003-3719-5270

In Hee Cho

https://orcid.org/0000-0003-0694-7249

Suk-Young Kim

https://orcid.org/0000-0003-1698-1547

Seung-Chul Hong

https://orcid.org/0000-0003-0828-2906

(c) This is an Open Access article distributed under the terms of the Creative Commons Attribution Non-Commercial License (https://creativecommons.org/licenses/by-nc/4.0) which permits unrestricted non-commercial use, distribution, and reproduction in any medium, provided the original work is properly cited.
Background and Objective This study aimed to investigate the changes in sleep quality with increasing age and the effect of age on the components of the Pittsburgh Sleep Quality Index (PSQI).

Methods We used data from the Community Health Survey conducted by the Korea Center for Disease Control and Prevention in 2018. A total of 228340 participants in this nationwide survey. Sleep quality was assessed using the PSQI. Adults aged $\geq 19$ years were divided into six age groups and one-way analysis of variance (one-way ANOVA) was used to compare the mean values of PSQI of each group. By comparing the scores for each PSQI component in those aged $\geq 65$ years and $<65$ years, we aimed to reveal the differences in special components according to age group.

Results In total, 223334 respondents were included in the study. Based on a one-way ANOVA, the PSQI score generally increased with age. Although the average PSQI score of patients in their 40 s was lower than that of patients in their 30s, there was no significant difference between the two groups ( $\mathrm{p}=0.11$ ). When the PSQI component was compared between the population aged over and under 65 years, the population aged $\geq 65$ years scored higher in most components. In contrast, daytime dysfunction scored higher in the population aged $<65$ years.

Conclusions Sleep quality tends to decrease with increasing age. Several factors, including physiological changes, underlying physical conditions, and psychosocial factors, may contribute to a decrease in sleep quality with age.

Sleep Med Res 2021;12(2):155-160

Keywords Age; Sleep quality; Analysis of variance.

\section{INTRODUCTION}

With increase in life expectancy, there is growing interest in quality of life. Sleep is receiving increasing attention among the elderly [1]. Recently, the proportion of the elderly population in Korea has increased rapidly, entering an aging society with $16.5 \%$ of the population being over the age of 65 years by 2021, according to Statistics Korea. Statistics Korea predicts that the elderly population will continue to increase [1]. According to previous studies, approximately $40 \%$ of the elderly complain of some form of sleep discomfort, and there is a report that the prevalence of insomnia in the elderly population in Korea is greater than $50 \%[2,3]$.

According to the normal aging process of the body, sleep structure and circadian rhythm change. Therefore, it is necessary to understand the normal sleep physiology of older adults. Elderly people often complain of difficulty falling asleep, which is largely attributed to a decrease in total sleep time [4,5]. Additionally, it is known that the ratio of slow wave sleep (SWS or N3) and rapid eye movement (REM) sleep decreases in the elderly [4,5]. Elderly people often complain that they wake up frequently during sleep, and are always in light sleep. Waking after sleep onset (WASO) generally increases with age [1]. The circadian rhythm of sleep is affected by ag- 
ing $[4,6]$. In the elderly, the sleep phase advances, leading to early sleep onset, waking up, and daytime sleepiness [4]. However, changes in normal sleep structure cannot be considered pathological. This suggests that sleep disturbance in the elderly is not an inherent process of aging [7]. Sleep problems in the elderly are affected by several factors, such as various underlying diseases, medications, psychosocial factors, and environmental changes, such as hospital admissions or nursing homes $[8,9]$.

Previous studies have reported a decrease in sleep quality in the elderly, however, no large-scale study evaluating the sleep quality by age group through a nationwide survey has been conducted. By dividing the participants into six age groups, we examined the sleep quality not only of the elderly, but also of all age groups. Therefore, in this study, the sleep quality of various age groups was evaluated using a nationwide survey. In addition, we investigated the differences between those over and under the age of 65 years with respect to the components of sleep quality. Based on the its definition by the World Health Organization, we categorized individuals over 65 years of age as elderly.

\section{METHODS}

\section{Study Design and Population}

This study used data from the 2018 Community Health Survey (CHS), a cross-sectional, nationwide survey. The Community Health Survey is conducted annually by the Korea Center for Disease Control and Prevention to assess the health status of adults over 19 years of age with a sample size of 900 [10]. The sampling units were selected using a two-stage stratified sampling method [10]. They used resident registration address data as the sampling frame [10]. Primary sampling locations and secondary sampling households were selected by probability-proportional-to-size sampling and systematic sampling, respectively [10]. The survey was conducted using a computer-assisted personal interview conducted by trained investigators [10]. The survey include various questions on demographic information, health behaviors, medical history, quality of life, and personal hygiene [10]. The total number of participants in the survey was 228340. For this study we excluded all individuals who did not respond to the PSQI question ( $\mathrm{n}=5006$ ). In total, 223334 eligible participants were included in this study.

\section{Pittsburgh Sleep Quality Index (PSQI)}

PSQI is a self-report on subjective sleep quality over the last 4 weeks with 18 questions [11,12]. The 18 items of the PSQI form a seven-component score ranging from 0 to 3 (sleep quality, sleep latency, sleep duration, sleep efficiency, sleep disturbances, sleep medication, and daytime dysfunction) that can be summed to obtain a general score [11]. Component scores range from 0 (no difficulty) to 3 (severe difficulty) and, when summed, produce a global score ranging from 0 to 21 . Higher scores indicate poorer sleep quality [11].

\section{Statistical Analysis}

The collected data were analyzed using SPSS win 18.0 (IBM Corp., Armonk, NY, USA), and the statistical significance was set at $\mathrm{p}<0.05$. For comparison by age group, the study participants were divided into 29 years or younger, 30-39 years, 4049 years, $50-59$ years, $60-69$ years, and $\geq 70$ years. One-way analysis of variance (ANOVA) was used to compare the mean PSQI values of each group. In addition, the Dunnett T3 method was used to compare the two groups by post hoc analysis because equal variance could not be assumed. Thereafter, the study participants were divided into groups under 65 and over 65 years of age. Differences in the PSQI components between the two groups were compared using t-tests.

\section{Ethics Statement}

The raw CHS data were downloaded from the CHS website after obtaining permission from the administrator of the CHS website (2021). All study procedures were conducted with the approval of the Institutional Review Board (IRB) of St. Vincent's Hospital, Catholic University of Korea (approval number: VC21ZASI0246).

\section{RESULTS}

\section{Demographic Characteristics}

Of the total number of 223334 study participants, $44.9 \%$ were male and $55.1 \%$ were female. By age group, $10.4 \%, 12.5 \%, 16.3 \%$, $19.6 \%, 18.6 \%, 22.7 \%$ were under 29 years, $30-39$ years, $40-49$ years, 50-59 years, 60-69 years, and over 70 years, respectively. Regarding marital status, $15.2 \%$ were single and $67.1 \%$ were married. The PSQI score distribution was $56.4 \%(0-4)$, and $43.6 \%$ (5-21) (Table 1).

\section{Comparison of PSQI Mean Scores for the Six Age Groups}

When comparing the mean PSQI scores of the six groups from the age of 29 years or younger to the age of 70 years or older, the scores tended to increase. Consequently, sleep quality decreased with increasing age. However, the mean PSQI score was higher in the 30s than in the 40s group, and there was no significant difference between the two groups $(\mathrm{p}=0.11)$ (Table 2).

The percentage of individuals with PSQI scores higher than 5 was $36.4362 \%$ in the age group of $19-29$ years, which was the lowest percentage. This ratio increased with age, similar to the mean PSQI value. On the other hand, the percentage of individuals with PSQI scores higher than 5 was greater in those in their 30 s than in those in their 40s. For those over 70 years of age, the percentage of PSQI scores exceeding 5 points was $53.8770 \%$, which was greater than half (Table 2). 
One-way ANOVA was used to compare the mean PSQI scores among the six age groups. Differences were considered statistically significant at $\mathrm{p}$-value $\leq 0.05$. Moreover, Dunnett's T3 method was applied to compare the mean PSQI scores of the two groups as a post-hoc analysis. Applying Levene's test to the test of equal variances, the p-value was lower than 0.05 . Thus, the Dunnett T3 method was selected because equal variance could not be assumed. As a result, it was confirmed that there was a significant difference between the $\geq 70$-year-old group and the remaining five age groups, with a p-value $<0.05$ (Table 3).

Table 1. Sociodemographic characteristics of participants $(n=$ 223334)

\begin{tabular}{lc}
\hline \multicolumn{1}{c}{ Characteristics } & $\mathrm{n}(\%)$ \\
\hline Sex & $100210(44.9)$ \\
Male & $123124(55.1)$ \\
Female & \\
Age (yr) & $23183(10.4)$ \\
Under the 29 & $27849(12.5)$ \\
30-39 & $36314(16.3)$ \\
$40-49$ & $43683(19.6)$ \\
50-59 & $41608(18.6)$ \\
60-69 & $50697(22.7)$ \\
Over the 70 & \\
Marriage status & $34038(15.2)$ \\
Single & $149864(67.1)$ \\
Married & $3031(1.4)$ \\
Separated & $8696(3.9)$ \\
Divorced & $27411(12.3)$ \\
Widowed & $294(0.1)$ \\
Non-responder & \\
PSQI & $125950(56.4)$ \\
0-4 & $97384(43.6)$ \\
5-21 & \\
\hline PSQ Pittsburgh Slep Quatidy
\end{tabular}

PSQI, Pittsburgh Sleep Quality Index.

\section{Comparison of PSQI Component Scores Between the Age Groups Over 65 Years and Under 65 Years}

A significant difference was found between the two age groups in all seven components $(\mathrm{p}<0.001)$. In all components except 'daytime dysfunction', the age group over 65 years had a higher PSQI score than that of the age group under 65 years. In other words, the age group under 65 years had better overall sleep quality than the age group over 65 years, but the age group under 65 years had more severe daytime dysfunctions (Table 4).

\section{DISCUSSION}

This study was conducted with a large sample group obtained from the Community Health Survey, which revealed an association between quality of sleep and age. When adults over 19 years of age were divided into six age groups and PSQI scores were compared, it was confirmed that the average PSQI score increased with age. In addition, when the scores of each PSQI component were compared between the age $\geq 65$ years group and the group $\leq 65$ years, sleep quality was low in all components except for the 'daytime dysfunction' component in the $\geq 65$ years group.

In previous studies, a number of research results have been reported that the quality of sleep decreases with age $[13,14]$. However, no age-related differences have been reported in local studies [15]. In a local study, 208 subjects aged 20-60 years were included. The number of subjects was small, and elderly individuals over the age of 60 years were not included [15]. Therefore, this study overcame the limitations of previous studies involving small groups.

In this study, several factors explained the decrease in subjective sleep quality with increasing age. First, sleep quality may deteriorate due to physiological changes that occur with aging. With normal aging, the total sleep time decreases, and the ratio of slow wave and REM sleep decreases [4,5]. Moreover, the elderly wake up frequently during sleep and fall asleep and wake up earlier than before [1]. These changes may have resulted in higher PSQI scores as people aged.

Second, older adults often have multiple underlying medical conditions that can have a detrimental effect on sleep quality.

Table 2. Average PSQI score by age group

\begin{tabular}{|c|c|c|c|c|c|c|}
\hline Age (yr) & $\begin{array}{l}\text { Number of participants } \\
\qquad(\mathrm{N}=223334)\end{array}$ & $\begin{array}{c}\text { Mean value } \\
\text { of PSQI }\end{array}$ & $\begin{array}{l}\text { Poor sleep quality } \\
\text { (PSQI > 5), } \%\end{array}$ & $\begin{array}{l}\text { Standard } \\
\text { deviation }\end{array}$ & $\begin{array}{l}\text { Standard } \\
\text { error }\end{array}$ & $95 \% \mathrm{CI}$ \\
\hline Under the 29 & 23183 & 4.1511 & 36.4362 & 2.91927 & 0.01917 & $4.1135-4.1887$ \\
\hline $30-39$ & 27849 & 4.4483 & 39.7429 & 2.95397 & 0.0177 & $4.4137-4.4830$ \\
\hline $40-49$ & 36314 & 4.3345 & 37.9303 & 2.8498 & 0.01495 & $4.3052-4.3638$ \\
\hline $50-59$ & 43683 & 4.6624 & 41.2082 & 3.10092 & 0.01484 & $4.6333-4.6915$ \\
\hline $60-69$ & 41608 & 5.0106 & 45.1356 & 3.30815 & 0.01622 & $4.9789-5.0424$ \\
\hline Over the 70 & 50697 & 5.7341 & 53.8770 & 3.60604 & 0.01602 & $5.7027-5.7655$ \\
\hline
\end{tabular}

PSQI, Pittsburgh Sleep Quality Index; CI, confidence interval. 
Table 3. One-way ANOVA and Post-hoc analysis (comparison between the mean PSQI scores of the two groups)

\begin{tabular}{lccccc}
\hline \multicolumn{5}{c}{ One-way ANOVA } \\
\hline Setween groups & 67668.039 & 5 & Mean square & F value & p-value \\
Within groups & 2270076.525 & 223328 & 13533.608 & 1331.424 & $<0.001$ \\
Total & 2337744.563 & 223333 & 10.165 & & \\
\hline \multicolumn{1}{c}{ Variable 1 } & Variable 2 & Mean difference & Standard deviation & p-value & 95\% CI \\
\hline Over the 70 & Under the 29 & 1.58298 & 0.025 & 0.038 & $1.4997-1.6662$ \\
& $30-39$ & 1.28574 & 0.024 & 0.027 & $1.2104-1.3611$ \\
& $40-49$ & 1.39959 & 0.022 & $<0.001$ & $1.3364-1.4628$ \\
& $50-59$ & 1.07168 & 0.022 & $<0.001$ & $1.0106-1.1328$ \\
& $60-69$ & 0.72344 & 0.023 & $<0.001$ & $0.6589-0.788$ \\
\hline
\end{tabular}

PSQI, Pittsburgh Sleep Quality Index; CI, confidence interval.

Table 4. Comparison of PSQI components for age group (T-test) $(n=223334)$

\begin{tabular}{|c|c|c|c|c|c|c|}
\hline PSQI component & Age & $\mathrm{n}$ & Average & Mean difference (95\% CI) & T statistics & p-value \\
\hline \multirow[t]{2}{*}{ 1. Sleep quality } & Under the 65 & 153281 & 1.0794 & $-0.15259(-0.15895,-0.14623)$ & -49.063 & $<0.001$ \\
\hline & Over the 65 & 70053 & 1.2368 & & & \\
\hline \multirow[t]{2}{*}{ 2. Sleep latency } & Under the 65 & 153281 & 0.8311 & $-0.25411(-0.26342,-0.24481)$ & -54.515 & $<0.001$ \\
\hline & Over the 65 & 70053 & 1.0874 & & & \\
\hline \multirow[t]{2}{*}{ 3. Sleep duration } & Under the 65 & 153281 & 0.8688 & $-0.10358(-0.11268,-0.09448)$ & -23.308 & $<0.001$ \\
\hline & Over the 65 & 70053 & 0.9759 & & & \\
\hline \multirow[t]{2}{*}{ 4. Sleep efficiency } & Under the 65 & 153281 & 0.3965 & $-0.23961(-0.248,-0.23122)$ & -56.42 & $<0.001$ \\
\hline & Over the 65 & 70053 & 0.637 & & & \\
\hline \multirow[t]{2}{*}{ 5. Sleep disturbances } & Under the 65 & 153281 & 0.8201 & $-0.24268(-0.24713,-0.23823)$ & -108.368 & $<0.001$ \\
\hline & Over the 65 & 70053 & 1.0638 & & & \\
\hline \multirow[t]{2}{*}{ 6. Sleep medication } & Under the 65 & 153281 & 0.061 & $-0.11095(-0.11613,-0.10577)$ & -42.581 & $<0.001$ \\
\hline & Over the 65 & 70053 & 0.1721 & & & \\
\hline \multirow[t]{2}{*}{ 7. Daytime dysfunction } & Under the 65 & 153281 & 0.4541 & $0.04573(0.03920,0.05225)$ & 13.571 & $<0.001$ \\
\hline & Over the 65 & 70053 & 0.4094 & & & \\
\hline \multirow[t]{2}{*}{ Global PSQI } & Under the 65 & 153281 & 4.5057 & $-1.0578(-1.08813,-1.02747)$ & -68.364 & $<0.001$ \\
\hline & Over the 65 & 70053 & 5.5635 & & & \\
\hline
\end{tabular}

PSQI, Pittsburgh Sleep Quality Index; CI, confidence interval.

A previous study found that in the elderly population aged 65 years and older, sleep problems were reported in 36\% without comorbidities, whereas the rate of sleep problems with four or more comorbidities increased to 69\% [7]. Another study showed that the PSQI score increased as the number of comorbidities increased [16]. In particular, sleep quality was lower in subjects with comorbidities, including psychiatric diseases, cancer, neurological conditions, and angina [16].

Third, drug and substance use can exacerbate sleep problems in older adults. Elderly individuals often take a variety of medications. Some drugs can induce arousal, resulting in changes in the structure of sleep with consequent sleep disturbances [17]. Sleep problems in the elderly are also exacerbated by a decrease in the rate of metabolism, absorption, distribution, and excretion of drugs [17]. Drugs that potentially cause sleep disturbance include antidepressants such as selective serotonin reuptake inhibitors, antihypertensive drugs, bronchodilators, diuretics, beta blockers, and corticosteroids $[17,18]$.

Fourth, psychosocial factors should also be fully considered in sleep disorders in the elderly. After retirement, the elderly have more flexible sleep schedules than before due to disappearance of regular routines. Thus, retirees may have more time to nap or lie down [7]. In addition, social activity also decreases, making many older people feel bored and lonely [7]. Furthermore, different lifestyles change the sleeping habits of older adults. Moreover, older people often experience the death of a spouse or close 
friend, so they have a period of mourning that sometimes leads to depression, anxiety disorders, and substance abuse [19]. Additionally, the elderly often face the burden of caring for their families or spouses. Consequently, older people often complain of significant levels of stress, which in turn increases the risk of sleep disorders [20,21]. Moreover, the elderly with deterioration of health may experience changes in their sleep environment as a result of admission to a nursing home or hospitalization; these may also affect their sleep $[8,9]$.

In contrast, in the case of daytime dysfunction in the PSQI component, the score was lower in the population over 65 years that in the population under 65 years. It is interesting to note that, unlike with other items, only those aged 65 years and over performed better in this component. This may be because the population aged $\geq 65$ years spends less time on work, physical activity, and social activities than the younger and middle-aged populations. Thus, the amount of discomfort arising from daytime sleepiness is small because the underlying daytime activity is insignificant [22].

A higher mean PSQI value was measured in those in their 30s than in those in their $40 \mathrm{~s}$, with a difference of 0.11 . Although the difference was not large, it is an exception in that the average PSQI score increased as age increased. Similarly, there were more participants in their 30s with PSQI scores higher than 5 than for those in their 40s. In recent years, marriage and childbirth in Korea have been delayed to the early 30 s, leading to major changes in lifestyle in the 30s. Sleeping with a spouse and raising young children may change the sleeping environment. In addition, changes caused by forming a new family may act as new stressors in the 30-year-old population, which may affect sleep quality.

A surprising finding in this study was that the percentage of participants with PSQI scores higher than 5 was over 30\%, even among young adults under the age of 29 years. This suggests that the importance of sleep problems in young adults should be given attention for appropriate evaluation and treatment.

This study had certain limitations. First, it was a cross-sectional study. Therefore, we cannot prove causality that age is the cause of worsening sleep quality. In addition, the survey results may be inaccurate, as the person interviewing the participant was not a sleep-knowledgeable medical professional. Third, in the community health survey, the average sleep time was based on the respondent's memory. Therefore, there was a high possibility of recall bias.

Nevertheless, this study had several strengths. First, it is a large community-based study that reflects the trend of the entire population, unlike previous studies with small groups. Additionally, unlike previous studies that did not involve different age groups in the analysis, this study carried out a detailed analysis to uncover the influence of increasing age and showed a correlation between age and sleep quality.

\section{Conclusion}

In this study, we found that sleep quality decreased with age. According to our results, several factors such as comorbidities and drugs along with physiological changes in old age may affect sleep. Future studies are needed to confirm the relationship between various factors that affect sleep quality in older adults.

\section{Availability of Data and Material}

All data generated or analyzed during the study are included in this published article (and its supplementary information files).

\section{Author Contributions}

Conceptualization: Hong SC, Kim M. Data curation: Kim TW, Kim SM, Kim SY. Funding acquisition: Hong SC. Investigation: Hong SC. Methodology: Kim TW, Kim SM. Resources: Lee J, Kim S. Software: Kim SY, Lee J, Kim S. Supervision: Hong SC. Writing-original draft: Kim M. Writing - review \& editing: Um YH, Kim TW, Seo HJ, Jeong JH, Cho IH.

\section{Conflicts of Interest}

The authors have no potential conflicts of interest to disclose.

\section{Funding Statement}

None.

\section{Acknowledgements}

For this study, we used the Korea Community Health Survey data, conducted by the Korea Centers for Disease Control and Prevention.

\section{REFERENCES}

1. Kim L, Kang SG. Sleep physiology and common sleep disorders in the elderly. Sleep Med Psychophysiol 2007;14:5-12.

2. Vitiello MV. Sleep disorders and aging: understanding the causes. $J$ Gerontol A Biol Sci Med Sci 1997;52:M189-91.

3. Yang CK, Yoo SY, Joo YH, Hahn HM. Sleep habits and sleep disorders among the elderly between 65-84 years who are living in a part of $\mathrm{Pu}-$ san. Sleep Med Psychophysiol 1997;4:66-76.

4. Ohayon MM, Carskadon MA, Guilleminault C, Vitiello MV. Metaanalysis of quantitative sleep parameters from childhood to old age in healthy individuals: developing normative sleep values across the human lifespan. Sleep 2004;27:1255-73.

5. Edwards BA, O’Driscoll DM, Ali A, Jordan AS, Trinder J, Malhotra A. Aging and sleep: physiology and pathophysiology. Semin Respir Crit Care Med 2010;31:618-33.

6. Mattis J, Sehgal A. Circadian rhythms, sleep, and disorders of aging. Trends Endocrinol Metab 2016;27:192-203.

7. Miner B, Kryger MH. Sleep in the aging population. Sleep Med Clin 2020;15:311-8.

8. McCurry SM, Logsdon RG, Teri L, Gibbons LE, Kukull WA, Bowen JD, et al. Characteristics of sleep disturbance in community-dwelling Alzheimer's disease patients. J Geriatr Psychiatry Neurol 1999;12:53-9.

9. Schnelle JF, Cruise PA, Alessi CA, Ludlow K, al-Samarrai NR, Ouslander JG. Sleep hygiene in physically dependent nursing home residents: behavioral and environmental intervention implications. Sleep 1998;21:515-23.

10. Kim YT, Choi BY, Lee KO, Kim H, Chun JH, Kim SY, et al. Overview of Korean community health survey. J Korean Med Assoc 2012;55:7483.

11. Buysse DJ, Reynolds CF 3rd, Monk TH, Berman SR, Kupfer DJ. The Pittsburgh Sleep Quality Index: a new instrument for psychiatric practice and research. Psychiatry Res 1989;28:193-213.

12. Pilz LK, Keller LK, Lenssen D, Roenneberg T. Time to rethink sleep quality: PSQI scores reflect sleep quality on workdays. Sleep 2018;41: 


$$
\text { zsy029. }
$$

13. Wong WS, Fielding R. Prevalence of insomnia among Chinese adults in Hong Kong: a population-based study. J Sleep Res 2011;20:117-26.

14. Kay DB, Dzierzewski JM. Sleep in the context of healthy aging and psychiatric syndromes. Sleep Med Clin 2015;10:11-5.

15. Kim JA, Kang SW. Relationship among sleep quality, heart rate variability, fatigue, depression, and anxiety in adults. Korean J Adult Nurs 2017;29:87-97.

16. Hayashino Y, Yamazaki S, Takegami M, Nakayama T, Sokejima S, Fukuhara S. Association between number of comorbid conditions, depression, and sleep quality using the Pittsburgh Sleep Quality Index: results from a population-based survey. Sleep Med 2010;11:366-71.

17. Lichstein KL, Wilson NM, Johnson CT. Psychological treatment of sec- ondary insomnia. Psychol Aging 2000;15:232-40.

18. Neubauer DN. Sleep problems in the elderly. Am Fam Physician 1999; 59:2551-8, 2559-60.

19. Shear MK. Clinical practice. Complicated grief. N Engl J Med 2015;372: 153-60.

20. McCurry SM, Logsdon RG, Teri L, Vitiello MV. Sleep disturbances in caregivers of persons with dementia: contributing factors and treatment implications. Sleep Med Rev 2007;11:143-53.

21. McKibbin CL, Ancoli-Israel S, Dimsdale J, Archuleta C, von Kanel R, Mills P, et al. Sleep in spousal caregivers of people with Alzheimer's disease. Sleep 2005;28:1245-50.

22. Li J, Vitiello MV, Gooneratne NS. Sleep in normal aging. Sleep Med Clin 2018;13:1-11. 